\title{
Diagnostic ipsilateral central neck dissection may reduce undertreatment of initially low-risk papillary thyroid cancer
}

\author{
Robert KRÁLIK ${ }^{1, *}$, Marianna GRIGEROVÁ ${ }^{2}$ Eva TAKÁCSOVÁ ${ }^{3}$ Iveta WACZULÍKOVÁ ${ }^{4}$, Štefan DURDÍK ${ }^{1}$
}

${ }^{1}$ Department of Surgical Oncology, St. Elisabeth's Cancer Institute, Comenius University, Bratislava, Slovakia; ${ }^{2}$ Department of Endocrinology, St. Elizabeth's Cancer Institute, Bratislava, Slovakia; ${ }^{3}$ Department of Nuclear Medicine, St. Elizabeth's Cancer Institute, Comenius University, Bratislava, Slovakia; ${ }^{4}$ Department of Nuclear Physics and Biophysics, Division of Biomedical Physics, Faculty of Mathematics, Physics and Informatics, Comenius University, Bratislava, Slovakia

${ }^{*}$ Correspondence: robert.kralik@ousa.sk

Received August 25, 2020 / Accepted October 27, 2020

\begin{abstract}
Although small papillary thyroid cancer (PTC) patients are considered as low-risk population, approximately 5-20\% of these patients relapse after surgery. The objective of this single-center retrospective study was to identify risk factors, which could help to distinguish patients who would need additional treatment after surgery. A total of 268 patients (39 men, 229 women, median age 49 years) underwent surgery between 2007-2015, and fulfilled inclusion criteria: tumor size $\leq 20$ $\mathrm{mm}$, absence of metastatic lymph nodes (LN) in the lateral neck compartment (LC), and absence of local invasion. Total thyroidectomy was performed in 252 cases, in 221 cases with central neck compartment (CC) dissection. The outcome - a more aggressive disease - was defined as the presence of metastases in the LNLC or in distant organs found during follow-up. A median follow-up was 117 months. Overall, 41 patients experienced the outcome with a median time-toevent of 18 months. Male gender $(\mathrm{OR}=2.2, \mathrm{p}=0.049)$, extra-thyroidal extension ETE $(\mathrm{OR}=2.61, \mathrm{p}=0.015)$, and metastases in LNCC $(\mathrm{OR}=4.21, \mathrm{p}<0.001)$ were associated with worse outcome. Multivariable analysis and stratification according to ETE revealed an effect modification with a higher effect of the positive LNCC on the outcome among patients without ETE than in those with ETE. Our findings advocate placing greater emphasis on the role of LNCC metastases in the absence of ETE. In clinically node-negative tumors intraoperative examination of CC on the side of the tumor followed by CC dissection if metastatic lymphadenopathy is present could play an important role in the stratification of patients with small-size PTC.
\end{abstract}

Key words: low-risk papillary thyroid cancer, central neck dissection, endocrine, disease management, evidence-based choice of treatment

The vast majority of papillary thyroid cancers (PTCs) are small tumors characterized by an innocuous nature and excellent prognosis [1]. The reported 5-year survival rates are $99.8 \%$ for PTCs located only in the thyroid gland, $97 \%$ when cancer has spread to the regional lymph nodes (LN), and $57 \%$ when it metastasizes to distant organs [2]. For small intraparenchymal tumors, the risk of disease recurrence is $1-5 \%$. The presence of LN metastases increases it to $20 \%$ [3]. Although the percentage of patients with recurrent disease is small, the absolute number is growing. ATA guidelines 2015 brought a new look at PTC management preferring a less radical therapeutic approach [3]. Prophylactic central compartment (CC) neck dissection is still debated and in general not recommended for small cancers [3].

We focused on small PTCs (up to $2 \mathrm{~cm}$ ) which have been considered low-risk tumors pre-operatively, yet during the follow-up they turned out to be more aggressive cancers. Some of the known risk factors such as substantial extrathy- roidal extension (ETE) and lateral compartment (LC) LN metastases can be identified by modern ultrasonography $[4$, 5]. We aimed to identify additional pre- and peri-operative risk factors, which would help to stratify patients for appropriate individualized treatment already at the time of initial diagnosis.

\section{Patients and methods}

We performed a retrospective, monocentric, observational study and retrieved data of 312 patients, with classical PTC $\leq 20 \mathrm{~mm}$ in diameter, who underwent thyroid surgery in our clinical setting between the years 2007-2015 (Figure 1). Patients with known metastatic LNLC or with clinically evident ETE before surgery were excluded (44 patients). Inclusion criteria were fulfilled by 268 patients: 39 males and 229 females with similar median age (47 and 50 years respectively, $\mathrm{p}=0.725$ ) and with male to female ratio reflecting those 
reported epidemiologic studies conducted in iodine-sufficient parts of the world [3].

Total thyroidectomy was performed in 252 cases (94.0\%), in 221 (82.5\%) with CC dissection. Out of them, 249 (92.9\%) patients received radioactive iodine treatment and had a post-therapeutic scintigraphy scan (eventually SPECT/CT) performed and stimulated thyroglobulin level examined. The collected data were based on the known risk factors for the outcome - a more aggressive disease, which required extensive therapy. The presence of a mutation in the BRAF V600 gene was investigated from formalin-fixed paraffinembedded surgically removed tumors. Altogether a subgroup of 129 patients with available data on the BRAF mutation was analyzed with respect to the outcome and compared with results obtained for the whole group.

The outcome was defined as the presence of metastases in LNLC or of distant metastases found after the initial surgery. Associations between the outcome and patients' characteristics were statistically evaluated using univariate (an unpaired t-test for continuous and $\chi^{2}$ tests for categorical predictors) and multivariable (Cox-proportional hazard regression) analyses. The latter is a semi-parametric method that fits Cox's proportional hazards model for time-to-event

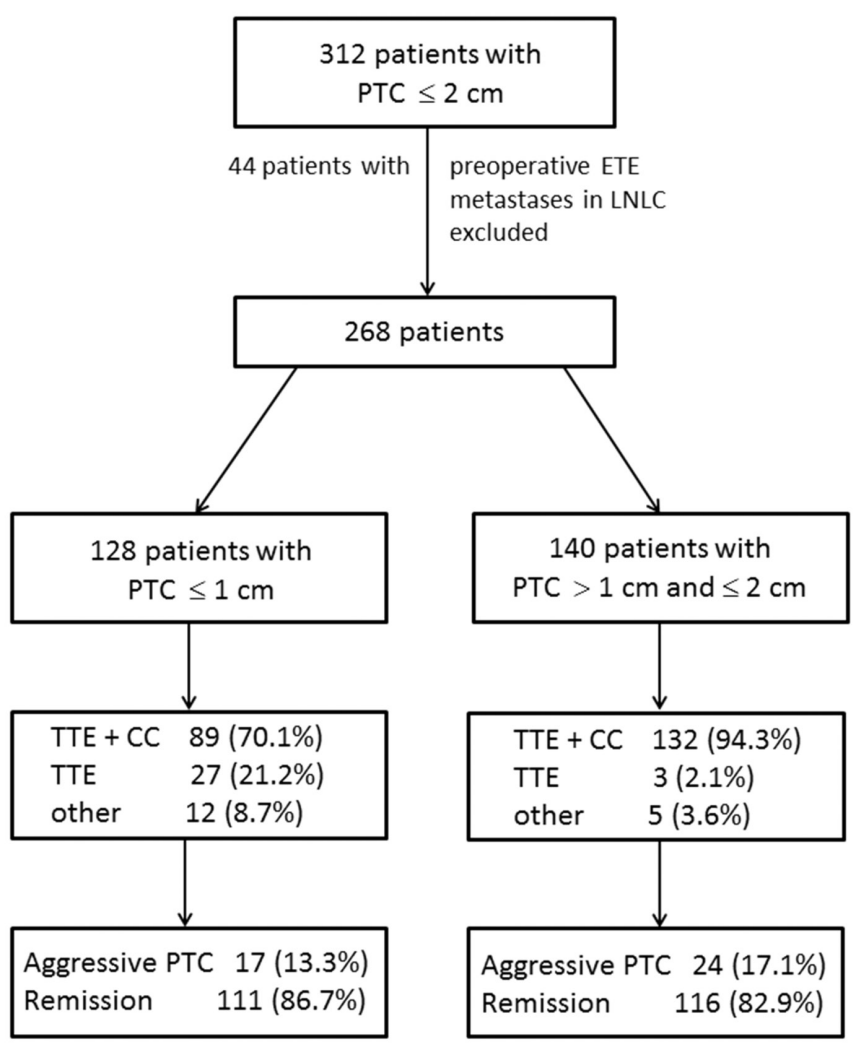

Figure 1. Scheme of the study design and patient selection. Abbreviations: PTC - papillary thyroid cancer; ETE - extra-thyroidal extension; LNLC - lymph nodes in the lateral neck compartment; TTE - total thyroidectomy; TTE+CC - total thyroidectomy central neck dissection performed outcomes on one or more predictors. The time-to-event was defined as the time from surgery to diagnosing the metastatic disease at either of the sites. The effect size of each explanatory variable was expressed in relative metrics OR (odds ratio) in the univariate (unadjusted) analysis and HR (hazard ratio) in the multivariable analysis, both indicating the degree of association found between an independent variable and the outcome. Statistical analyses were performed using Microsoft Office Excel 2010 (Microsoft Corporation) and StatsDirect $^{\circledR}$ 3.2.7 (StatsDirect Ltd., Cheshire, UK).

This study was approved by the Institutional Review Board on the 8th of June, 2017. All procedures performed in studies involving human participants were in accordance with the ethical standards of the institutional and/or national research committee and with the 1964 Helsinki declaration and its later amendments or comparable ethical standards. Informed consent was obtained from all individual participants included in the study.

\section{Results}

Overall, $15.3 \%$ (41/268) of initially clinically low-risk PTCs were diagnosed as more aggressive tumors during follow-up with a median time-to-event of 18.3 months (ranging from 2.0 to 109.6 months). The median follow-up time was 162.4 months (ranging from 58.4 to 385.7 months). Univariate analysis testing the simple relationship between each explanatory variable and the outcome (Table 1) revealed that more aggressive PTC was significantly associated with perioperatively identified LN metastases in the central neck compartment and with ETE $(\mathrm{OR}=4.21, \mathrm{p}<0.001$ and $\mathrm{OR}=2.61, \mathrm{p}=0.015$, respectively). At the time of surgery, LNCC metastases were found in $71(26.5 \%)$ patients. In 31 (11.6\%) patients they were ipsilateral, in $18(6.7 \%)$ patients bilateral, and $22(8.2 \%)$ patients did not have a specified site of the metastasis.

Among other patients' characteristics the male gender and angioinvasion contributed to more aggressive PTC, the latter significantly $(\mathrm{OR}=2.22, \mathrm{p}=0.088$ and $\mathrm{OR}=2.29$, $\mathrm{p}=0.035)$. Mutation in the BRAF V600 gene was detected in $54 \%$ of the patients (70/129); 14 patients positive for BRAF mutation were diagnosed with more aggressive disease $(\mathrm{OR}=2.29, \mathrm{p}=0.172)$. Cross-classification of the outcome by $B R A F$ positivity stratified by age showed a higher percentage of $B R A F$ positive cases with aggressive disease in younger than in older patients $(\mathrm{OR}=5.50$ vs. $\mathrm{OR}=2.57)$. Based on the fact that the subgroup of patients with $B R A F$ examination and the whole group were alike in all relevant characteristics, we could make an extrapolation of the results obtained on this subgroup by a proportional doubling of the frequencies observed in the age strata. Thus, we achieved the sample size of 258 (approximately the same size as the investigated group) while keeping the ORs - that means the effect sizes - in the age strata constant but this time with statistically significant pooled OR $(\mathrm{p}=0.043)$. 
Table 1. Clinicopathological characteristics of patients with PTC in different disease states and their association with a more aggressive disease.

\begin{tabular}{|c|c|c|c|c|c|c|}
\hline & & Total & Aggressive & Remission & $\mathrm{OR}^{\mathrm{a}}$ & p-value \\
\hline Number of cases & & 268 & $41(15.3 \%)$ & $227(84.7 \%)$ & n.a. & n.a. \\
\hline Age (years) & mean \pm S.D. & $48.3 \pm 13.99$ & $45.5 \pm 15.11$ & $48.7 \pm 13.73$ & n.a. & 0.173 \\
\hline \multirow[t]{3}{*}{ Age category } & $<35$ years & 54 & $12(22.2 \%)$ & $42(77.8 \%)$ & $1.82^{\mathrm{b}}$ & $0.095^{\mathrm{c}}$ \\
\hline & $<35-60$ years & 151 & $19(12.6 \%)$ & $132(87.4 \%)$ & & \\
\hline & $\geq 60$ years & 63 & $10(15.9 \%)$ & $53(84.1 \%)$ & & \\
\hline \multirow[t]{2}{*}{ Gender } & male & 39 & $10(25.6 \%)$ & $29(74.4 \%)$ & 2.22 & 0.088 \\
\hline & female & 229 & $31(13.5 \%)$ & $198(86.5 \%)$ & & \\
\hline \multirow[t]{2}{*}{ Tumor size } & $<1-2>\mathrm{cm}$ & 140 & $24(17.1 \%)$ & $116(82.9 \%)$ & 1.35 & 0.40 \\
\hline & $<1 \mathrm{~cm}$ & 128 & $17(13.3 \%)$ & $111(86.7 \%)$ & & \\
\hline \multirow[t]{3}{*}{ Autoimmune thyroiditis } & no & 130 & $23(17.7 \%)$ & 107 (82.3\%) & 1.41 & 0.069 \\
\hline & yes & 136 & $18(13.2 \%)$ & $118(86.8 \%)$ & & \\
\hline & unknown & 2 & $0(0 \%)$ & $2(100 \%)$ & & \\
\hline \multirow[t]{2}{*}{ Multifocality } & yes & 65 & $14(21.5 \%)$ & $51(78.5 \%)$ & 1.79 & 0.116 \\
\hline & no & 203 & $27(13.3 \%)$ & $176(86.7 \%)$ & & \\
\hline Extrathyroidal & yes & 47 & $13(22.7 \%)$ & $34(72.3 \%)$ & 2.61 & 0.015 \\
\hline \multirow[t]{2}{*}{ extension } & no & 219 & $28(12.8 \%)$ & $191(87.2 \%)$ & & \\
\hline & unknown & 2 & $0(0 \%)$ & $2(100 \%)$ & & \\
\hline \multirow[t]{2}{*}{$B R A F^{\mathrm{d}}$} & mutant & 70 & $10(14.3 \%)$ & $60(85.7 \%)$ & 2.29 & 0.172 \\
\hline & wild type & 59 & $4(6.8 \%)$ & $55(93.2 \%)$ & & \\
\hline \multirow[t]{3}{*}{ Angioinvasion } & yes & 42 & $11(26.2 \%)$ & $31(73.8 \%)$ & 2.29 & 0.035 \\
\hline & no & 224 & $30(13.4 \%)$ & $194(86.6 \%)$ & & \\
\hline & unknown & 2 & $0(0 \%)$ & $2(100 \%)$ & & \\
\hline \multirow[t]{6}{*}{ LNCC } & positive & 71 & $22(28.6 \%)$ & $49(71.4 \%)$ & 4.21 & $<0.001$ \\
\hline & ipsilateral side & 31 & $8(25.8 \%)$ & $23(74.2 \%)$ & & \\
\hline & bilateral side & 18 & $11(61.1 \%)$ & $7(38.9 \%)$ & & \\
\hline & contralateral side & 0 & $0(0 \%)$ & $0(0 \%)$ & & \\
\hline & side not specified & 22 & $3(13.6 \%)$ & $19(86.4 \%)$ & & \\
\hline & negative & 197 & $19(9.6 \%)$ & $178(90.4 \%)$ & & \\
\hline \multirow[t]{8}{*}{ TTE } & yes & 252 & $41(16,3 \%)$ & $211(83.7 \%)$ & 3.1 & 0.486 \\
\hline & with CC dissection & 221 & $37(16.7 \%)$ & $184(83.3 \%)$ & & \\
\hline & without CC dissection & 30 & $3(10.0 \%)$ & $27(90.0 \%)$ & & \\
\hline & unknown & 1 & $1(100 \%)$ & $0(0 \%)$ & & \\
\hline & no & 16 & $0(0 \%)$ & $16(100 \%)$ & & \\
\hline & with CC dissection & 9 & $0(0 \%)$ & $9(100 \%)$ & & \\
\hline & without CC dissection & 7 & $0(0 \%)$ & $7(100 \%)$ & & \\
\hline & unknown & $0(0 \%)$ & $0(0 \%)$ & $0(0 \%)$ & & \\
\hline
\end{tabular}

Continuous data are presented as means \pm S.D. Categorical data are presented as absolute counts with percent of row total. athe unadjusted odds ratio calculated as the ratio of the odds of having an event in the upper row category to the odds of having an event in the lower row category of the predictor variable. b the unadjusted odds ratio calculated as the ratio of the odds of having aggressive disease in the age category $<35$ years to the odds of having aggressive disease in the age category $\geq 35$ years. The choice of cut-off points for age categories was based on the study by Takacsova et al. [11]. To compute the unadjusted ORs $\chi^{2}$ test of independence or Fischer exact test were applied. cthe Cochran-Armitage $\chi^{2}$ test of linear trend for age-risk categories as suggested by Takacsova et al. [11]. ' a subgroup of patients with BRAF gene mutation test performed $(\mathrm{N}=129)$. Association of a more aggressive papillary thyroid cancer disease with BRAF positivity stratified by age categories yielded OR=2.42 and p=0.160 (c.f. Results). Abbreviations: PTC - papillary thyroid cancer; OR - odds ratio; P - probability; S.D. - standard deviation; n.a. - not applicable; LNCC - lymph nodes in the central neck compartment; TTE - total thyroidectomy

The greater tumor size (above $1 \mathrm{~cm}$ ), multifocality, and an absence of autoimmune thyroiditis were not confirmed as significant risk factors on univariate analysis $(\mathrm{OR}=1.35$, $\mathrm{p}=0.400 ; \mathrm{OR}=1.79, \mathrm{p}=0.116$ and $\mathrm{OR}=1.41, \mathrm{p}=0.069$, respectively). Results of fitting the multiple regression models confirmed the results of univariate analysis for variables tumor size, multifocality, and autoimmune thyroiditis. The low explanatory power of the variable tumor size for the prediction of the more aggressive disease can be explained by the fact that the greater tumor size, as well as the presence of ETE and angioinvasion, all were significantly associated with the most significant risk factor for more aggressive disease - the presence of metastases in LNCC (Table 2). When stratified by the presence of ETE, the odds ratio for the association between the risk factor and more aggressive PTC was slightly higher for patients without ETE $(n=219)$ than that those with 
Table 2. Clinicopathological characteristics of patients with PTC in the studied tumor size categories.

\begin{tabular}{|c|c|c|c|c|c|c|}
\hline & & Total & $\begin{array}{l}\text { Tumor size } \\
<1-2>\mathrm{cm}\end{array}$ & $\begin{array}{c}\text { Tumor size } \\
<1 \mathrm{~cm}\end{array}$ & $\mathrm{OR}^{\mathrm{a}}$ & p-value \\
\hline Number of cases & & 268 & $140(52.2 \%)$ & $128(47.8 \%)$ & n.a. & n.a. \\
\hline Age (years) & mean $\pm \mathrm{SD}$ & $48.3 \pm 13.99$ & $45.5 \pm 15.11$ & $47.1 \pm 14.54$ & n.a. & 0.144 \\
\hline \multirow[t]{3}{*}{ Age category } & $<35$ years & 54 & $32(59.3 \%)$ & $22(40.7 \%)$ & $1.43^{\mathrm{b}}$ & $0.384^{\mathfrak{c}}$ \\
\hline & $<35-60$ years & 151 & $77(51.0 \%)$ & $74(49.0 \%)$ & & \\
\hline & $\geq 60$ years & 63 & $31(49.2 \%)$ & $32(50.8 \%)$ & & \\
\hline \multirow[t]{2}{*}{ Gender } & male & 39 & $24(61.5 \%)$ & $15(38.5 \%)$ & 1.56 & 0.209 \\
\hline & female & 229 & $116(86.5 \%)$ & $113(13.5 \%)$ & & \\
\hline \multirow[t]{3}{*}{ Autoimmune thyroiditis } & no & 130 & $76(58.5 \%)$ & $54(41.5 \%)$ & 1.67 & 0.036 \\
\hline & yes & 136 & $62(45.6 \%)$ & $74(55.4 \%)$ & & \\
\hline & unknown & 2 & $2(100 \%)$ & $0(0 \%)$ & & \\
\hline \multirow[t]{2}{*}{ Multifocality } & yes & 65 & $30(46.2 \%)$ & $35(53.8 \%)$ & 0.73 & 0.259 \\
\hline & no & 203 & $110(54.2 \%)$ & $93(45.8 \%)$ & & \\
\hline \multirow[t]{3}{*}{ Extrathyroidal extension } & yes & 47 & $32(68.1 \%)$ & $15(31.9 \%)$ & 2.27 & 0.014 \\
\hline & no & 219 & $106(48.4 \%)$ & $113(51.6 \%)$ & & \\
\hline & unknown & 2 & $2(100 \%)$ & $0(0 \%)$ & & \\
\hline \multirow[t]{3}{*}{ Angioinvasion } & yes & 42 & $29(69.1 \%)$ & $13(30.9 \%)$ & 2.35 & 0.015 \\
\hline & no & 224 & $109(48.7 \%)$ & $115(51.3 \%)$ & & \\
\hline & unknown & 2 & $2(100 \%)$ & $0(0 \%)$ & & \\
\hline \multirow[t]{2}{*}{ LNCC } & positive & 71 & $46(64.8 \%)$ & $25(35.2 \%)$ & 2.02 & 0.014 \\
\hline & negative & 197 & $94(47.7 \%)$ & $103(52.3 \%)$ & & \\
\hline \multirow[t]{8}{*}{ TTE } & performed & 252 & $135(53.6 \%)$ & $117(46.4 \%)$ & 2.54 & 0.083 \\
\hline & with CC dissection & 221 & $132(59.7 \%)$ & $89(40.3 \%)$ & & \\
\hline & without CC dissection & 30 & $3(10 \%)$ & $27(90 \%)$ & & \\
\hline & unknown & 1 & $0(0 \%)$ & $1(100 \%)$ & & \\
\hline & not performed & 16 & $5(31.2 \%)$ & $11(68.8 \%)$ & & \\
\hline & with CC dissection & 9 & $5(55.6 \%)$ & $4(44.4 \%)$ & & \\
\hline & without CC dissection & 7 & $0(0 \%)$ & $7(100 \%)$ & & \\
\hline & unknown & 0 & $0(0 \%)$ & $0(0 \%)$ & & \\
\hline
\end{tabular}

Continuous data are presented as means \pm standard deviations. Categorical data are presented as absolute counts with percent of column total, unless otherwise stated. athe ratio of the odds of having a tumor size of $1-2 \mathrm{~cm}$ in the upper row category to the odds of having that tumor size in the lower row

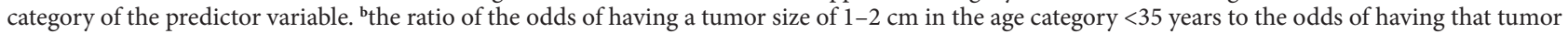
size in the age category $\geq 35$ years. The choice of cut-off points for age categories was based on the study by Takacsova et al. [11]. To compute the ORs $\chi^{2}$ test of independence or Fischer exact test were applied. 'the Cochran-Armitage $\chi^{2}$ test of linear trend for age-risk categories as suggested by Takacsova et al. [11]. Abbreviations: PTC - papillary thyroid cancer; TU - tumor; OR - odds ratio; P - probability; S.D. - standard deviation; n.a. - not applicable; LNCC lymph nodes in the central neck compartment; TTE - total thyroidectomy

Table 3. Multivariable analysis of selected clinicopathologic variables and their association with a more aggressive disease in patients with smallsize papillary thyroid cancer.

\begin{tabular}{lccccc}
\hline Variable & B & $\begin{array}{c}\text { Standard } \\
\text { Error }\end{array}$ & p-value & HR & 95\% CI \\
\hline Gender M & 0.363 & 0.3716 & 0.3282 & 1.44 & $0.69-2.98$ \\
Age (years) & -0.014 & 0.0121 & 0.2332 & 0.98 & $0.96-1.01$ \\
ETE & 0.834 & 0.5656 & 0.1403 & 2.30 & $0.76-6.98$ \\
ETE $\times$ LNCC & -0.503 & 0.7119 & 0.4799 & 0.61 & $0.15-2.44$ \\
LNCC & 1.214 & 0.3876 & 0.0017 & 3.37 & $1.58-7.20$ \\
\hline
\end{tabular}

The likelihood $\chi^{2}$ test statistic was 21.713 and corresponding $\mathrm{p}$-value $=$ 0.0008 . The combined effect of ETE and LNCC on the more aggressive disease calculated from the regression coefficients yielded the hazard ratio of $4.69\left(\mathrm{HR}=\mathrm{e}^{(0.834-0.503+1.214)}=4.69\right)$. Abbreviations: $\mathrm{B}$ - regression coefficients; $\mathrm{P}$ - probability; HR - hazard ratio; 95\% CI - 95\% confidence interval; M male; ETE - extrathyroidal extension; LNCC - lymph nodes in the central neck compartment
ETE with the overall (pooled) OR significantly different from one $(\mathrm{OR}=3.68 ; 95 \% \mathrm{CI}: 1.80-7.55 ; \mathrm{p}=0.0004$; lower part of Figure 2). $\chi^{2}$ test for heterogeneity of all odds ratios was not significant $\left(\chi^{2}=0.209, D F=1, p=0.6474\right)$, however, the association between the risk factor and the outcome was different for different ETE strata suggesting that an effect modification might have been present.

We further explored this possibility by performing the multiple Cox-proportional hazard regression analysis. To select the most appropriate form of LNCC variable (ordinal or binary), we first investigated the effect of an increased number of metastases in LNCC on the time to the outcome. The estimated hazard ratio (HR) for patients without ETE with more than one positive LN was 3.96 (95\% CI: 1.62-9.68; $\mathrm{p}=0.003$ ). The HR for only one positive LN was slightly 
reduced $(3.25$; 95\% CI: $1.18-8.97)$ but remained significant $(p=0.023)$. The average hazard ratios for the presence of one $(\mathrm{HR}=3.15 ; 95 \% \mathrm{CI}: 0.77-12.83)$ or more metastases in $\mathrm{CC}(\mathrm{HR}=1.75 ; 95 \% \mathrm{CI}: 0.47-6.52)$ among patients with ETE did not reach statistical significance $(p=0.110$ and 0.404 , respectively) likely due to the lower number of patients in this stratum. It was therefore reasonable to stick to binary LNCC predictor coded as metastasis present/absent. The final model (introduced in Table 3) was built from the main independent variables LNCC and ETE, involving the interaction term LNCC $\times$ ETE as an additional independent variable. The model was adjusted for any possible influence of age and gender. We found that the model taking into account the interaction between LNCC and ETE status was significant $(\mathrm{p}=0.0008)$ and more closely fit the observed data than did its simpler alternative $\left(\chi^{2}=21.713\right.$ vs. $\left.\chi^{2}=20.632\right)$. Even if the interaction term per se was not statistically significant, it improved the descriptive performance of the model.

\section{Discussion}

Low-risk PTCs according to ATA 2015 Guidelines [3] do not need a traditionally recommended complex oncological treatment. In our clinical experience, up to $10 \%$ of those patients develop biochemical or structural evidence of persistent/recurrent disease within two years and 15-20\% of patients within 10 years after surgery. A relatively short median time-to-event (18.3 months) found in our study suggests rather persistent than the recurrent disease. Thus, it is important to identify vulnerable patients at increased risk of more aggressive disease already at the time of initial diagnosis.

\begin{tabular}{|c|c|c|c|c|}
\hline \multirow[b]{2}{*}{ ETE } & \multirow[b]{2}{*}{ LNCC } & \multicolumn{2}{|c|}{ PTC outcome } & \multirow[b]{2}{*}{ Total } \\
\hline & & Aggressive & Remission & \\
\hline \multirow{2}{*}{ no } & positive & 13 & 33 & 46 \\
\hline & negative & 15 & 158 & 173 \\
\hline Total for no & & 28 & 191 & 219 \\
\hline \multirow{2}{*}{ yes } & positive & 9 & 15 & 24 \\
\hline & negative & 4 & 19 & 23 \\
\hline Total for yes & & 13 & 34 & 47 \\
\hline \multirow{2}{*}{ unknown } & positive & 0 & 1 & 1 \\
\hline & negative & 0 & 1 & 1 \\
\hline \multicolumn{2}{|c|}{ Total for unknown } & 0 & 2 & 2 \\
\hline \multicolumn{2}{|l|}{ Grand Total } & 41 & 227 & 268 \\
\hline
\end{tabular}

\section{Odds ratio meta-analysis plot [fixed effects]}

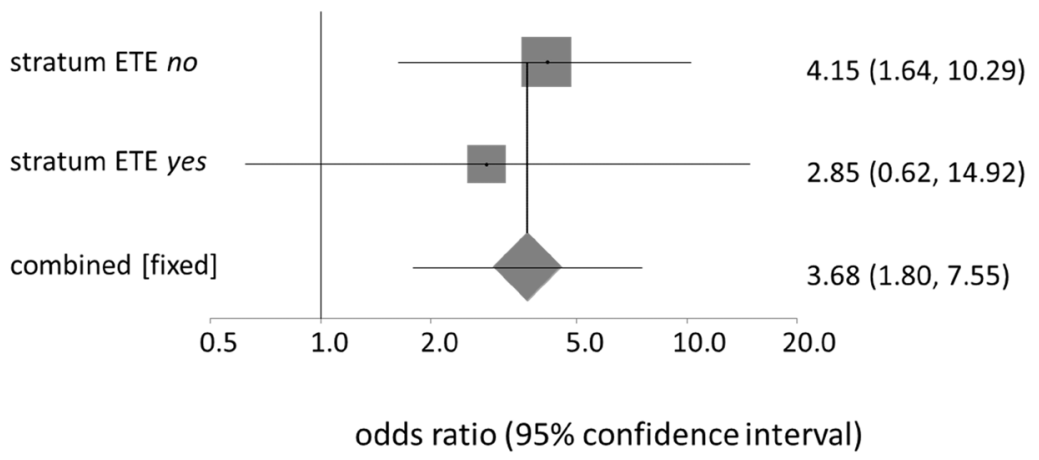

Figure 2. Descriptive results on disease outcomes of PTC patients with respect to the perioperative presence of metastatic disease, stratified by extrathyroidal extension. The computed odds for having more aggressive PTC in patients with the risk factor (present metastases in the LNCC) stratified by the presence or absence of extrathyroidal extension are shown in the forest plot. The association between the risk factor and outcome across the strata was tested using the Mantel-Haenszel $\chi^{2}$ test: pooled OR=3.68 $(95 \% \mathrm{CI}: 1.80-7.55) . \chi^{2}($ test $\mathrm{OR}$ differs from 1$)=12.461 ; \mathrm{p}=0.0004$. $\chi^{2}$ for heterogeneity (test that all odds ratios are equal) $=0.209, \mathrm{DF}=1, \mathrm{p}=0.6474$.). Abbreviations: OR - odds ratio; $95 \% \mathrm{CI}-95 \%$ confidence interval; PTC - papillary thyroid cancer; ETE - extrathyroidal extension categorized as present (coded ETE yes) or absent (coded ETE no); LNCC - lymph nodes in the central neck compartment categorized as positive or negative presence of metastases 
Whereas several factors have been consistently reported as risk factors for recurrence of PTC [6], much less information is available on risk stratification of tumors $<2 \mathrm{~cm}$. On univariate analysis, male gender, extrathyroidal extension, vascular invasion, LNCC metastases (all known risk factors) [5-9], and supposedly also $B R A F$ mutation [5, 10-12] were significantly associated with disease aggressiveness in the consistence with ATA Guidelines [3]. The present study supports the view of current literature summarized e.g. in [3] that in small-size PTC a greater size of the tumor might not be a negative prognostic factor per se. We did not find a statistically significant association between aggressiveness and tumor size when tumors smaller than $1 \mathrm{~cm}$ were compared to tumors sized $1-2 \mathrm{~cm}$.

Conflicting results are found regarding the independent prognostic significance of gender and vascular invasion toward recurrence, distant metastases, and death [3]. Since correlation analysis revealed a strong association of vascular invasion with metastases in LNCC, our attention was mainly drawn to the prognostic significance of ETE, LNCC, their mutual relationships, and impact on the outcome.

When analyzing the prognostic significance of LNCC metastases in the stratified analysis, we found out that the effect size expressed by OR was surprisingly different in patients with and without ETE (2.85 and 4.15, respectively; Figure 2). Metastases in the LNCC were found in $26.5 \%$ of the tumors $<2 \mathrm{~cm}$ in total. The results mirrored those obtained by the stratified univariate analysis - LNCC were significantly predictive of more aggressive disease independently of ETE. When accompanied by ETE, the HR rose to 4.69 (Table 3), which was less than the estimate of 5.33 from the model without the interaction term (not shown). It may be partially explained by the fact that ETE and LNCC metastases were not truly independent, but mutually correlated to some extent. Since the association between metastasis in LNCC and the outcome was different for different strata of ETE, the effect modification might have been present, likely due to residual metastatic LNCC in some ETE-negative patients. Assuming that the interaction was not specified a priori and that the interaction term was not statistically significant, we consider this finding as preliminary. On the other hand, we have to keep in mind that the parsimonious model by ignoring the interaction apparently attenuated the effect of negative ETE ( $\mathrm{HR}=1.67)$.

Our findings would advocate placing greater emphasis on the role of LNCC metastases in the absence of ETE if the assumption on the effect modification is correct. It also adheres to the fact that performing of central neck dissection was significantly associated with the higher numbers of the perioperatively found positive LNCC. Randolph et al. revealed that the prognostic significance of nodal metastases should be based on the number and size of positive LN as well as on the presence or absence of extra-nodal extension [7]. We divided and statistically evaluated our group of patients into three subgroups: with no, one, and more LNCC metas- tases. Patients with no metastases had statistically significant better prognosis compared to both other subgroups. There was no statistical difference between the groups with one and more metastases. It seems that the ability of the tumor to metastasize itself and not the number of lymph nodes affected has clinical importance, which has also been suggested by other researchers [13]. Metastases in LNCC are difficult to diagnose pre-operatively $[14,15]$. It seems that intraoperative examination of $\mathrm{CC}$ with the histopathologic assessment of lymph nodes $>5 \mathrm{~mm}$ could be beneficial in the management of PTC.

To summarize, when interpreting the relationship between the presence of LNCC metastases and more aggressive disease, the ETE status should also be considered. We drew special attention to the patients without ETE for whom limited treatment would be recommended. In this group of patients, the presence of metastases in LNCC was associated with a four times higher risk of persistent/recurrent disease compared to patients without metastases (Figure 2). Without performing CC dissection, $7.3 \%$ of patients would be undertreated, which is in accordance with the literature [6]. The performance of routine prophylactic CC dissection for PTC is still an area of debate $[16,17]$ and generally, it is not recommended in the early stages of the disease [17]. Japanese practice is to perform extensive surgery for all PTCs. If the diagnosis of PTC is known before surgery then both central and lateral neck dissections on the side of the tumor are recommended. With this surgical approach, they achieved in the Japanese population the recurrence rate of all PTCs (including high-risk cancers) similar to low-risk cancers [9]. Based on our results, we suggest performing an intraoperative examination of CC followed by diagnostic ipsilateral central neck dissection if LN greater than $5 \mathrm{~mm}$ are present as a standard surgical procedure in all patients with low-risk PTC especially when unilateral lobectomy is considered. Unilateral central neck dissection carries a low risk of surgical complications, virtually the same as lobectomy. We are aware that the proposed surgical strategy is not impeccable as up to $6.7 \%$ of patients (in our cohort none) can have metastatic lymphadenopathy only on the contralateral side of CC [18] but it can significantly decrease the number of undertreated patients. Histological examination of central neck lymph nodes can help to identify patients who would benefit from completion thyroidectomy and radioactive iodine treatment $[19,20]$.

In conclusion, the new ATA 2015 Guidelines make advances in the management of low-risk differentiated thyroid cancer. Thorough pre- and intra-operative management are necessary to accurately identify low-risk patients with the aim of avoiding both under and over-treatment. In times when the rationale of central neck dissection is discussed, the procedure performed on the side of the tumor in appropriately selected cases could play an important role in the risk-stratification of patients with small-size papillary thyroid cancer, particularly in cases without extra-thyroidal extension. 


\section{References}

[1] COOPER DS, COSIMO DURANTE C. (Eds.). Thyroid Cancer. A Case-Based Approach. Switzerland: Springer International Publishing; 2016, pp 412. ISBN 978-3-31922401-5 https://doi.org/10.1007/978-3-319-22401-5

[2] SIEGEL RL, MILLER KD, JEMAL A. Cancer statistics 2018. CA Cancer J Clin 2018; 68: 7-30. https://doi.org/10.3322/ caac. 21442

[3] HAUGEN BR, ALEXANDER EK, BIBLE KC, DOHERTY GM, MANDEL SJ et al. 2015 American Thyroid Association management guidelines for adult patients with thyroid nodules and differentiated thyroid cancer: the American Thyroid Association guidelines task force on thyroid nodules and differentiated thyroid cancer. Thyroid 2016; 26: 1-133. https:// doi.org/10.1089/thy.2015.0020

[4] KLUIJFHOUT WP, PASTERNAK JD, LIM J, KWON JS, VRIENS MR et al. Frequency of High-Risk Characteristics Requiring Total Thyroidectomy for $1-4 \mathrm{~cm}$ Well-Differentiated Thyroid Cancer. Thyroid 2016; 26: 820-824. https://doi. org/10.1089/thy.2015.0495

[5] WERNER SC, INGBAR SH, BRAVERMAN LE, COOPER D. Werner \& Ingbar's The Thyroid: A Fundamental and Clinical Text, $10^{\text {th }}$ Edition, Philadelphia: Lippincott Williams \& Wilkins; 2012. ISBN: $9781451120639145112063 \mathrm{X}$

[6] GUO K, WANG Z. Risk factors influencing the recurrence of papillary thyroid carcinoma: a systematic review and metaanalysis. Int J Clin Exp Pathol 2014; 7: 5393-5403. https:// www.ncbi.nlm.nih.gov/pmc/articles/PMC4203153/

[7] RANDOLPH GW, DUH QY, HELLER KS, LIVOLSI VA, MANDEL SJ et al. The prognosis significance of nodal metastases from pappilary thyroid carcinoma can be stratified based on the size and number of metastatic lymph nodes, as well as the presence of extranodal extension. Thyroid 2012; 22: 1144-1152. https://doi.org/10.1089/thy.2012.0043

[8] PARK YM, LEE DY, OH KH, CHO JG, BAEK SK et al. Clinical implications of pathologic factors after thyroid lobectomy in patients with papillary thyroid carcinoma. Oral Oncology 2017; 75: 1-5. https://doi.org/10.1016/j.oraloncology.2017.10.012

[9] MATSUZU K, SUGINO K, MASUDO K, NAGAHAMA M, KITAGAWA K et al. Thyroid Lobectomy for Papillary Thyroid Cancer: Long-term Follow-up Study of 1,088 Cases. World J Surg 2014; 38: 68-79. https://doi.org/10.1007/ s00268-013-2224-1

[10] XING M, ALZAHRANI AS, CARSON KA, VIOLA D, ELISEI R et al. Association Between BRAF V600E Mutation and Mortality in Patients with Papillary Thyroid Cancer. JAMA 2013; 309: 1493-1501. https://doi.org/10.1001/ jama.2013.3190
[11] TAKACSOVA E, KRALIK R, WACZULIKOVA I, ZAVODNA K, KAUSITZ J. A different prognostic value of BRAFV600E mutation positivity in various age groups of patients with papillary thyroid cancer. Neoplasma 2017; 64: 156-164. https://doi.org/10.4149/neo_2017_120

[12] JOO JY, PARK JY, YOON YH, CHOI B, KIM JM et al. Prediction of occult central lymph node metastasis in papillary thyroid carcinoma by preoperative BRAF analysis using fineneedle aspiration biopsy: a prospective study. J Clin Endocrinol Metab 2012; 97: 3996-4003. https://doi.org/10.1210/ jc.2012-2444

[13] ALPERT EH, WENIG BM, DEWEY EH, SU HK, REIS LD et al. Size Distribution of Metastatic Lymph Nodes with Extranodal Extension in Patients with Papillary Thyroid Cancer: A Pilot Study. Thyroid 2015; 25: 238-241. https://doi. org/10.1089/thy.2014.0392

[14] YEH MW, BAUER AJ, BERNET V, FERRIS RL, LOEVNER LA et al. American Thyroid Association statement on preoperative imaging for thyroid cancer surgery. Thyroid 2014; 25: 3-14. https://doi.org/10.1089/thy.2014.0096

[15] KOUVARAKI MA, SHAPIRO SE, FORNAGE BD, EDEIKEN-MONRO BS, SHERMAN SI et al. Role of preoperative ultrasonography in the surgical management of patients with thyroid cancer. Surgery 2003; 134: 946-955. https://doi. org/10.1016/s0039-6060(03)00424-0

[16] CHAN AC, LANG BHH, WONG KP. The pros and cons of routine central compartment neck dissection for clinically nodal negative (cN0) papillary thyroid cancer. Gland Surgery 2013; 2: 186-195. http://gs.amegroups.com/article/ view/2971

[17] AGRAWAL N, EVASOVICH M, KANDIL E, NOURELDINE SI, FELGER EA et al. Indications and Extent of Central Neck Dissection for Papillary Thyroid Cancer: An American Head and Neck Society Consensus Statement. Head Neck 2017; 39: 1269-1279. http://dx.doi.org/10.1002/ hed.24715

[18] KOO BS, CHOI EC, YOON YH, KIM DH, KIM EH et al. Predictive factors for ipsilateral or contralateral central lymph node metastasis in unilateral papillary thyroid carcinoma. Ann Surg 2009; 249: 840-844. https://doi.org/10.1097/ SLA.0b013e3181a40919

[19] RUEL E, THOMAS S, PERKINS JM, ROMAN SA, SOSA JA. The Impact of Pathologically Positive Lymph Nodes in the Clinically Negative Neck: An Analysis of 39,301 Patients with Papillary Thyroid Cancer. Ann Surg Oncol 2017; 24: 1935-1942. https://doi.org/10.1245/s10434-016-5719-9

[20] QUI N, ZHANG L, JI HJ, CHEN JY, ZHU YX et al. Risk Factors for Central Compartment Lymph Node Metastasis in Papillary Thyroid Microcarcinoma: A Meta-Analysis. World J Surg 2015; 39: 2459-2470. https://doi.org/10.1007/s00268015-3108-3 